\title{
Vontade de beleza e ritual nas artes verbais ameríndias
}

\author{
Desire of beauty and ritual in Amerindian verbal arts \\ Voluntad de belleza y ritual en las artes verbales amerindias \\ Ana Lúcia Liberato Tettamanzy ${ }^{*}$ \\ Luciene Rivoire
}

\section{Resumo}

Este artigo se propõe a discutir uma prática estética que envolve narrativas orais. Quem Conta um Conto é um grupo vinculado à Universidade Federal do Rio Grande do Sul que tem experimentado atividades relacionadas a performances numa escola mbyá-guarani. Considerando a vontade de beleza que fundamenta a vida indígena, através da arte verbal tem sido possível aproximar diferentes poéticas e também favorecer o entendimento dos modos com que este povo se apropria criativamente de perspectivas alheias. Além disso, tem sido possível compreender as práticas artísticas ameríndias como meios rituais de manutenção do equilíbrio do cosmos e da comunidade.

Palavras-chave: Mbyá-Guarani, artes verbais, ritual, autoria.

\section{Abstract}

This essay aims at discussing an aesthetic practice involving storytelling. Quem Conta um Conto is a group connected with the Universidade Federal do Rio Grande do Sul that has been experimenting with activities related to oral narratives in a Mbyá-Guarani school. Considering the desire for beauty that underpins indigenous life, it has been possible, by means of verbal art, to understand the relationships between different kinds of poetics. Verbal art has also been a helpful tool in understanding the ways in which this community creatively borrows from other people's points of view. It has also been possible to understand Amerindian artistic practices as ritualistic means of maintaining both the balance of the cosmos and of the community.

Keywords: Mbyá-Guarani, verbal arts, ritual, authorship.

\section{Resumen}

Este artículo se propone discutir una práctica estética que involucra narrativas orales. Quem Conta um Conto es un grupo vinculado a la Universidade Federal do Rio Grande do Sul que ha experimentado actividades relacionadas con performances en una escuela mbyá-guarani. Considerando la voluntad de belleza que fundamenta la vida indígena, a través del arte verbal ha sido posible aproximar diferentes poéticas y también favorecer el entendimiento de los modos con que este pueblo se apropian creativamente de perspectivas ajenas. Además se ha podido comprender las prácticas artísticas amerindias como medios rituales de mantenimiento del equilibrio del cosmos y de la comunidad.

Palabras clave: Mbyá-Guarani, artes verbales, ritual, autoría.

\footnotetext{
* Doutora em letras (literatura brasileira) e professora da Universidade Federal do Rio Grande do Sul (UFRGS), Porto Alegre, RS, Brasil. Dorcid.org/0000-0001-7811-2190. E-mail: atettamanzy@terra.com.br

A* Arteterapeuta e mestre em artes cênicas pela Universidade Federal do Rio Grande do Sul (UFRGS), Porto Alegre, RS, Brasil.

(Dorcid.org/0000-0002-8130-6655. E-mail: lurivoire@gmail.com
} 
segurança. Segurança que não temos nós que tanto colecionamos espécimes raros, como desprezamos seus criadores.

Darcy Ribeiro

Não há distinção entre a beleza produtiva de uma panela para cozinhar alimentos, uma criança bem cuidada e decorada e um banco esculpido com esmero.

Els Lagrou

\section{O espaço-tempo das histórias}

Este texto nasce de perguntas, quase todas sem respostas. E, se há respostas, tendem a ser provisórias, suscetíveis a novas compreensões. $\mathrm{O}$ inacabamento deve-se à conjugação de pesquisa, extensão, vivência e performance na relação estabelecida por um grupo de contadores de histórias vinculado à universidade a partir de um convite de um professor mbyá-guarani. ${ }^{1} \mathrm{O}$ encontro ocorreu durante uma apresentação em exposição de arte guarani realizada no Museu da Universidade Federal do Rio Grande do Sul. Tratava-se da narração oral de histórias provenientes do corpus mítico e poético-narrativo desse povo, pesquisadas em sites e materiais audiovisuais e escritos.

A prática da narrativa oral numa aldeia veio a ser um desafio no sentido de que se cria uma forma de contar e um contexto enunciativo de algo que está numa fronteira. A experiência da diferença possibilita aos interlocutores das performances um olhar de si mesmos no espelho do outro. E isso só tem ocorrido porque existe um esforço mútuo em mediar as culturas e linguagens através de mecanismos tradutórios experimentados nos atos de narrar e de escutar. Uma das formas mais efetivas de efetivar essa copresença remete ao reconhecimento dos distintos modos de conhecer a realidade. Conforme o filósofo argentino Rodolfo Kusch (2009), no mundo indígena a realidade não é estável nem habitada por objetos, mas repleta de acontecimentos e movimentos que afetam o sujeito a partir de dentro. O autor refere o exemplo de um ancião indígena andino que, frente a um problema concreto - a falta de água na comunidade -, recusa o oferecimento de uma bomba hidráulica e busca os conhecidos mecanismos do ritual. Na sua perspectiva, apenas com a forma cunhada pela cultura seria possível comprometer o indivíduo e o vincular à sua comunidade através da ativação no presente de mecanismos e saberes do passado. Em outra situação, Kusch percebe como, ao contrário da ojeriza ocidental pelo descontrole propiciado pelas emoções, uma comunidade originária sustenta sua coerência interna através do fundo afetivo, revivido pelos rituais de tempos em tempos. Nessa perspectiva, o saber acessado pelos sentidos contribui para a manutenção do grupo e do cosmos:

Em tal universo, tomado como algo orgânico, total, diríamos um cosmo-animal, não cabe a distinção entre seus componentes; vale, antes de tudo, seu equilíbrio interno. O glorioso e ameaçador predomina sobre qualquer objeto. Daí a continuidade do saber no ritual. Um e outro convergem para equilibrar o cosmos (Kusch, 2009, p. 332, tradução nossa).

Considerando a alteridade posta em contato pelo ato de narrar oralmente, as histórias marcam um espaço em comum, o ritual da performance, de modo que os interditos podem, por vezes, circular a fim de tratar das incongruências e dos conflitos postos em cena. Foi assim que, durante uma tarde de brincadeiras cantadas, ocorreu a proposta de imitação de ruídos e posturas corporais de bichos. A certa altura, em vez de indicar um animal, um dos professores sugeriu às crianças que imitassem o juruá (termo que designa na língua guarani o branco, ou o não indígena, ou ainda, numa tradução literal-cultural, o que tem boca barbuda, que fala demais). Ato contínuo, passaram a urrar com estridente violência e a executar gestos agressivos. Esse evento pode ilustrar a definição de Daniel Mato (2005) sobre cultura: não é uma coisa ou objeto, mas uma mirada, uma perspectiva, um modo de olhar e interpretar as experiências sociais. Como explica o autor, quando se aproximam

\footnotetext{
${ }^{1}$ O processo tem início em 2011 na escola da aldeia Anhetengua, situada no bairro Lomba do Pinheiro, em Porto Alegre/RS, e tem continuidade desde 2015 na aldeia Yvy Poty, no município de Barra do Ribeiro/RS.
} 
diferentes racionalidades, efetivam-se tanto cruzamentos como desencontros. A colaboração intercultural é condição para que se traduzam, mais que palavras e ideias, visões de mundo e percepções. No caso em tela, a narrativa oral tem sido o dispositivo empregado na aldeia para cruzar perspectivas e interagir esteticamente com as cosmovisões e conhecimentos que na América Latina foram desqualificados (quando não destruídos) pelo colonialismo ocidental. É também, como na cena da brincadeira descrita acima, a possibilidade cósmica de, acessando o glorioso e o ameaçador, compreender de forma emocional e corpórea a violência colonial, ou seja, a palavra dita elucida e significa o vivido posto que procede da experiência coletiva, ainda mais sendo esta da ordem do trauma. O filósofo Walter Benjamin, marcado pela perseguição nazi-fascista e pela experiência da destruição em massa provocada pela grande guerra, interroga: pode a narração criar “o clima propício e a condição mais favorável de muitas curas?” (Benjamin, 1987, p. 269). A incorporação pelas crianças da agressividade do não indígena indica uma possibilidade de cura, já que nomeiam o indizível e dão forma e expressão a memórias dolorosas enquanto em contato com a alteridade, e efetivamente por causa dela.

Assim, estando ausente uma metodologia preconcebida ou fundamentada num trabalho de pesquisa formal, os movimentos e acontecimentos desses encontros (por vezes desencontros) com a perspectiva mbyá ocorrem, sobretudo, pela arte de narrar e pelos corpos. Uma preocupação envolvida nessa proposta diz respeito ao cuidado em construir relação dialógica atenta aos distintos modos de conhecer e estar no mundo, algo que o Grupo de contadores vem sistematicamente elaborando através de participações em estudos e ações de formação de professores indígenas. ${ }^{2}$ A metodologia antropológica traz vasta reflexão sobre os acordos mais ou menos tácitos que vão se estabelecendo na medida em que diferentes sistemas de conhecimento são colocados num mesmo espaço de ação e convivência. Em publicação resultante de evento organizado por Manuela Carneiro da Cunha e Pedro de Niemeyer Cesarino, são abordados os efeitos das políticas culturais para os índios e sobre os índios (ou das que os afetam de alguma maneira). O cerne do debate está no conceito de cultura "com aspas", desenvolvido pela antropóloga como sendo aquele que afeta a vivência dos grupos, uma vez que passa a ser lugar de negociações e mediações com a sociedade não indígena. A questão básica é observar "como se dá a indigenização da cultura" (Cunha, 2009, p. 314), quer dizer, como essa noção é transformada e apropriada pelos nativos na superação da dualidade entre o dentro e o fora em face das políticas públicas de patrimonialização de bens culturais de natureza imaterial e também diante de processos de escolarização nas terras indígenas. Um aspecto recorrente em várias análises diz respeito à presença do corpo como meio e suporte do conhecimento. O caso relatado sobre o kene (grafismos ou desenhos produzidos pelas mulheres do povo Huni Kuĩ) ilustra aspectos da problemática (Lima et al., 2016). Primeiro, por mostrar a distinta agência masculina e feminina: os primeiros, lideranças e professores, mais proficientes na língua portuguesa, pensavam no kene como "cultura" a ser valorizada fora da aldeia e em produções de materiais didáticos; já as segundas, que detêm o conhecimento sobre os desenhos, insistiam em enumerar como salvaguarda a compra de utensílios e ferramentas úteis, bem como a construção de casas de artesanato nas aldeias, que lhes permitiriam seguir vendendo e trocando. Além dessa diferença, o conhecimento tido como um "bem" interfere no entendimento dos Huni Kuĩ de que o desenho produz as pessoas, e importa mais pelo que faz do que pelo que quer dizer pois reside "no corpo, no caso primordialmente nos olhos e mãos da artesã, instâncias que devem ser objeto de uma construção cotidiana, e que por isso teriam pouca relação com as ações do Iphan" (Lima et al., 2016, p. 236). De nada valeriam, assim, certificações externas ao grupo se não mantivessem continuidade e significado os circuitos tradicionais de transmissão e produção dos kene.

\footnotetext{
${ }^{2}$ Temos participado de outras atividades e experiências acadêmicas ligadas aos povos indígenas do Sul do país que permitem complexificar a experimentação de um pensamento sensível através da arte verbal, como a participação, desde 2014, das aulas de língua guarani ministradas (como atividade de extensão) por Vherá Poty, jovem mbyá-guarani com diversificada atuação como liderança, educador, musicista, fotógrafo e criador audiovisual. Também fazemos parte, desde 2014, do grupo sediado na UFRGS que conduz o Programa Saberes Indígenas na Escola, dedicado à formação de cerca de 200 professores Kaingang e Guarani das escolas públicas do Estado do Rio Grande do Sul. Financiado pela Secretaria da Educação Continuada, Alfabetização, Diversidade e Inclusão do Ministério da Educação, visa ao fortalecimento das políticas públicas voltadas às escolas indígenas e a propostas pedagógicas diferenciadas pela valorização das línguas e cosmovisões originárias. Para ter acesso a mais dados sobre essa iniciativa, recomendamos a leitura do artigo "Um olhar sobre o olhar indígena e suas escol(h)as", de Magali Mendes Menezes et al. (2015).
} 
Essas considerações podem dar pistas sobre o sentido da prática de contação de histórias realizada. Não parece ser o caso típico de um aspeamento da cultura no sentido de que por conta de uma política pública ou de uma pesquisa na escola estivessem instados a representar sua cultura para outros. Contudo, não era dado de antemão o que efetivamente poderia ser compartilhado no espaço autorizado por eles, a escola, elemento que só muito recentemente foi aceito pelos Guarani, e com reservas. O contato com as crianças das séries iniciais, falantes apenas da língua materna, pareceu de início um limitador. Por que escutavam a narrativa oral dentro da escola, através da performance e do improviso dos Juruá numa língua outra, se o lugar da palavra - falada, entoada, cantada - é ao redor do fogo, na casa de cerimônia (opy), no colo materno? Dada a alegria com que reagiam às narrativas, era evidente que pelo corpo e pelos sentidos havia compreensão, logo, fruição estética. Com o tempo, ocorreram interaprendizagens das línguas e de brincadeiras corporais, percepção que o professor expressava ao seu modo. Certa vez, foi solicitado que ele atuasse numa história narrada pela contadora. Ele deveria representar as ações do protagonista masculino, um jovem guarani que se apaixona por uma moça branca (Mburukujá) e é assassinado a mando do pai da jovem. Esta, ao saber do corrido, crava a ponta de uma flecha no peito e jaz ao lado corpo do amado. Desse lugar brota a flor do maracujá. Feita uma primeira versão, em que o professor se projetou enfaticamente ao solo para marcar o desfecho trágico, retirou-se por uns instantes da sala. Quando retornou, usava um cocar e quis repetir o relato todo. Por alguma razão, sentiu necessidade de produzir seu corpo com o uso do adorno étnico. Queria marcar-se como índio para o público de não índios? Ou apenas queria, como observava nas práticas narrativas do grupo, empregar objeto cênico a fim de potencializar um efeito poético perante os que assistiam? Neste caso, experimentaria um espaço-tempo expandido, o do ritual performático em que ocorre uma transformação e produz o seu corpo? A nosso ver, interessava ao professor que os alunos tomem contato com falantes de língua portuguesa numa forma diferente (leia-se menos agressiva e mais respeitosa) das habituais para crianças e mulheres, no caso, as esparsas idas à cidade para negociar o artesanato - para eles a "caça na cidade". Através das histórias, apropriavam-se de meios de relação com a outra sociedade, e o mesmo ocorria por parte do grupo. Tempos depois, quando indagado sobre por que colocara o cocar (elemento que afirmou não usar em outros contextos), respondeu que queria deixar a história mais engraçada, possibilidade esta resultante, pelo menos em parte, de seu entendimento a respeito do caráter performático de nossas sessões de narração na aldeia.

Algo semelhante foi relatado na etnografia com os Maxacali, de Marina Guimarães Vieira (2016), que propõe uma analogia entre os cantos xamânicos, usados para pacificar os espíritos, e a escrita e a escola, usadas para pacificar os brancos, ou seja, como numa antropologia reversa (termo de Roy Wagner), estas produzem conhecimento sobre os brancos e um discurso para os brancos. Como explica Vieira, para este povo a condição humana é construída e assegurada por meio de cantos, num processo que se dá no corpo e através da relação com os espíritos e os parentes; tais cantos possuem donos, mas não autores, e demandam rituais, e, quando "apresentados em livros ou outros suportes despersonalizados, fora dos contextos específicos onde existem como subjetividades atreladas a pessoas de corpo presente, se tornam 'cultura Maxacali', objeto vendável sobre o qual todos os Maxakali desejam obter seu retorno" (Vieira, 2016, p. 250). Se, evidentemente, não se efetivaram experiências xamânicas nas práticas de narrativa oral, os corpos e as vozes personalizados na escola guarani criaram intersubjetividades ao traduzir saberes. Ainda assim, talvez seja mais uma estratégia criativa de pacificação da escola, que, como explica a especialista em educação escolar indígena, Dominique Tilkin Gallois, "é percebida ao mesmo tempo como instrumento de empoderamento para a 'autonomia' e também como uma armadilha para a domesticação de conhecimentos. As duas coisas acontecem, pois se trata de uma contradição inerente à escola" (Gallois, 2016, p. 509). De todo o modo, os Guarani e o grupo de contadores vêm produzindo juntos rituais na forma de eventos relacionais, e essa característica, como será visto mais adiante, é constituinte tanto das artes ameríndias como das artes contemporâneas. 


\section{As artes nos rituais e nas relações}

Como explicitam diversos estudos antropológicos de Darcy Ribeiro, a preocupação estética preside a vida nos grupos indígenas no Brasil; contudo, não se trata, como na cultura não indígena, de reservar à obra de arte o lugar de imanência e de domínio individual e (relativamente) original do ofício. Ao contrário, vários membros dos grupos manejam as técnicas e as reproduzem; esse fazer, contudo, extrapola as funções utilitárias (ainda que não as rejeite) e não se encontra submetido a uma economia de mercado, como ocorre na dita sociedade envolvente:

[...] o nosso "selvagem" vive uma vida farta e está seguro de que ele próprio é uma nobre criatura, capaz de tudo entender e de fazer muito bem ao menos algumas coisas. Mais horas ocupa um índio em satisfazer sua vontade de beleza, fazendo coisas belas, adornando seu corpo, cantando ou dançando, do que qualquer artista profissional nosso dedica a seu ofício, às vezes tão arduamente especializado que deixa de ser gozoso (Ribeiro, 1986b, p. 32).

Esse funcionamento explica a permanente atualização coletiva do que é belo, garantida não pelo acúmulo e pela posse de objetos, mas pela sua incessante reelaboração, seja nos atos cotidianos, seja nos momentos rituais, em suma, na vida e no corpo dos sujeitos. Tal compreensão difere da perspectiva dos ocidentais, que

[...] não dão todo o seu valor à tecnologia indígena e a própria arte moderna, como veremos adiante, tende a não considerar a presença do estético na prática indígena. Não se toma em consideração a densidade de significados que os objetos de produção indígena carregam.

O que talvez esteja no âmago desta diferença é que a arte, nas sociedades indígenas, está comprometida com outros fins sociais que aqueles a ela atribuídos na sociedade ocidental. É, até certo ponto, uma arte anônima, no sentido de que o sujeito criador são coletividades, ainda que seja sempre o indivíduo concreto quem dá a marca, o selo, o gesto particular. Neste sentido, caberia apontar os rituais como sendo, provavelmente, a forma mais condensada da arte indígena e da arte popular, por serem a síntese suprema de todas as manifestações de cultura corporal, de artes plásticas, de teatro, de poesia, de literatura, música e dança. Trata-se, sem dúvida, de uma experiência coletiva estetizada de uma maneira potente, concisa, densa (Vidal e Silva, 1995, p. 373, grifo nosso).

Posto isso, se pensarmos nos significados atribuídos pela sociedade não indígena à literatura, assim como à arte em geral, a autoria é compreendida principalmente como criação individual, e a obra pautada pelo alto grau de elaboração estética, via de regra desvinculada de funções sociais e do cotidiano. Diametralmente divergentes, tanto a criação como a recepção da arte indígena enfatizam os rituais como "experiência coletiva estetizada", que não dissocia o material e o simbólico, ou a criação e a vida.

Pelos ainda precários níveis de letramento e pela desigualdade social que marcam a sociedade brasileira, a fruição da literatura e da arte permanece, infelizmente, sendo privilégio de poucos e, como tal, signo de distinção social. Cabe observar, porém, que a complexidade das sociedades contemporâneas provocou uma disseminação das linguagens e dos meios e processos de produção, transmissão e recepção de conhecimentos e artes, de modo que segmentos periféricos e emergentes promovem outros circuitos de comunicação e de produção estético-cultural, revisitando cânones e provocando pautas políticas e de intervenção. À guisa de exemplo, cabe lembrar o surgimento no início deste século da chamada "literatura periférica", bem como a emergência de saraus, slams, cultura hip hop, editoras cartoneiras, arte de rua, enfim, variadas modalidades que deslocam das livrarias, galerias e museus para espaços públicos e mesmo para os meios virtuais modalidades compósitas e participativas de experiência literária e estética, em que ideias de copresença e coautoria fazem parte da natureza das manifestações.

À primeira vista, tal situação de instabilidade de fronteiras e rearranjo de paradigmas difere da forte presença dos meios de autoexpressão e criatividade nas criações milenares dos povos originários; no entanto, encontram-se pontos de contato desta tradição com a forma performativa e política do cenário artístico-cultural na contemporaneidade. Conforme Berta Ribeiro (1986a), a arte é composta de signos e representações simbólicas que dizem respeito à 
realidade do mundo conforme cada cultura a entende, com especial atenção, no caso das sociedades originárias, para as "artes da vida", ou seja, para instrumentos e utensílios, mas também para as técnicas que tornam a vida confortável e prazerosa. Noutros termos, fabricamse coisas que sejam bonitas e boas, não direcionadas para a contemplação. Sendo assim, nos contextos indígenas, a arte se baseia mais no processo do que nas coisas. Isso ilumina aspectos como a dimensão do ritual, em que eventos são significativos - gestos, palavras, objetos, tudo é simbólico. Tal compreensão dialoga com o registro de Darcy Ribeiro: a experiência estética nativa percorre desde os objetos até os corpos e acontecimentos em que a vontade de beleza se faz presente. De modo semelhante, algumas das possibilidades mais desafiadoras dos circuitos atuais das artes operam com relações de forma e expressão fora do indivíduo e ainda com a circulação de saberes e estéticas em atos cotidianos e rituais em que o corpo mesmo encena os códigos e valores da cultura: "o processo ritualístico é mais importante que a obra acabada. [...] tem raiz na importância da performance para as artes ameríndias [...] a arte contemporânea, cada vez mais, retira o foco do objeto e passa ao processo o status de obra, vide happenings, performances, instalações, videoinstalações, web art etc." (Lagrou, 2009, p. 111).

Ora, os significados diferenciados atribuídos à arte pelas sociedades indígenas, em diálogo com manifestaç̃es estético-culturais contemporâneas, muitas delas efetivadas em eventos nos espaços públicos, instabilizam o conceito de literatura monumento, restrita à bidimensionalidade do livro impresso e à leitura individualizada. A palavra escrita expande-se para o corpo em performance e para uma recepção coletivizada, em simultaneidade a outras linguagens e significações como a música, a dança, a festa, o sagrado. No campo dos estudos literários, são ainda escassas as abordagens das artes verbais nas cerca de 280 línguas indígenas faladas no Brasil atual. O crítico baiano Antônio Risério (1993) foi precursor nos estudos literários ao alertar para a supressão das poéticas ameríndias e africanas (definidas por ele como extraocidentais ou extraeuropeias) da história literária nacional. Os artigos de Risério procuram dissolver certos consensos sobre tais materiais. Ao definir o texto criativo - ou a poesia - como atributo do gênero humano presente em todas as épocas ou regiões, o autor desconstitui os que buscam na poesia primitiva uma forma inicial e inferior, ou que lhe atribuem negatividades como dependência da música e carência de autonomia estética pelo caráter coletivo e anonimato das criações. Refina tais argumentações com expansões do sentido de poesia nas criações tribais por conta de seu dinamismo, que não é apenas repetição, e da prática sígnica realizada sobre os materiais da linguagem: "Digamos ainda que os ameríndios possuem não apenas classificações da produção textual, mas também teorias da criação poética. Não há povo que não tenha pensado sobre a linguagem e suas múltiplas dimensões" (Risério, 1993, p. 169). É assim que a palavra é sonhada; ou é enfeitada pelos profetas na execução vocal que amplia as metáforas ou a musicalidade; ou ainda, posta pelos deuses e atualizada pelo poeta-xamã, pois "suas experiências extáticas repercutem criativamente no corpus mitológico da sociedade" (Risério, 1993, p. 171). Indo mais além, Risério reivindica um tratamento esteticamente eficaz para os que, sobretudo na área da antropologia, registram os cantos e narrativas ameríndios. Ainda que a passos lentos, empreendimentos que consideram as dimensões poéticas da performance ou mesmo análises das performances xamânicas vêm sendo contempladas em abordagens que aproximam linguística, antropologia e teorias estéticas e literárias. Devair Fiorotti propôs produtiva comparação dos erenkon (cantos dos Macuxi e Taurepang, da zona de fronteira do Estado de Roraima) com os haicai japoneses pelos atributos comuns de condensação, efemeridade e imagética intensa. A partir de entrevistas e tradução da produção artística pertencente "a um complexo sistema que envolve música, dança, canto, coreografia, pintura corporal e texto literário" (Fiorotti e Oliveira, 2016, p. 55), ressalta a ampliação do âmbito poético para as dimensões ritualísticas e performativas. Em perspectiva semelhante, o antropólogo e tradutor Pedro de Niemeyer Cesarino identifica nas artes verbais ameríndias densa articulação de procedimentos formais e retóricos (como as montagens e os paralelismos) com a visualização dos eventos que a pessoa cindida do xamã/cantador experiencia: a "economia discursiva e imagética de artes verbais xamanísticas, vale frisar, não é a do ouvir dizer narrativo, mas a da evidência direta das ações excorporadas do cantador" (Cesarino, 2006, p. 109). Ao longo do texto, Cesarino exemplifica através de cantos as modulações dos deslocamentos sociocósmicos experimentados pelo performer, que 
atualiza a capacidade tradutória do xamã ao mudar de corpo, ou seja, ao tornar-se outro. A base nessas leituras concentra-se nas propriedades relacionais das poéticas ameríndias, o que retorna ao sentido exposto anteriormente sobre a estetização do cotidiano nos corpos produzidos na vontade de reapresentação/atualização da beleza. Tal sentido vem orientando a prática narrativa na aldeia dos Mbyá-Guarani, conforme será relatado a seguir.

\section{Estética e ritual na experiência narrativa}

É sabido que contar histórias faz parte do aprendizado dos povos indígenas, com elas transmitem ensinamentos, realizam aconselhamentos para os mais novos, se divertem e tomam decisões. A arte verbal tem lugar central particularmente entre os Mbyá, que reconhecem, nas belas palavras (inspiradas pela divindade) e na eloquência, o sentido principal de seu modo de vida (Pissolato, 2008). A escola, via de regra, está associada à escrita da língua materna e ao ensino da língua portuguesa e de matérias não pertencentes à cultura originária, visto que a educação tradicional, que antecede o nascimento de cada um e persiste existência afora, é efetivada por todos da comunidade (crianças maiores ensinam às menores, os mais velhos subsidiam decisões coletivas e exercem a memória coletiva, bichos, plantas e espíritos e possuem agências no mundo humano).

A história Mbyá é resgatada cotidianamente. Sociedade oral por excelência, em que a retórica tem lugar de destaque, o conhecimento das "belas palavras", base dos ensinamentos, é o atributo mais desejado. A conservação do saber e das tradições é valorizada justamente por seu componente de oralidade. $O$ desenvolvimento ou aprimoramento do ser humano, do ser Mbyá, passa pelo aperfeiçoamento de seu discurso oral, pela penetração que este pode alcançar no seio da comunidade. Leva-se ainda em consideração (e neste aspecto se descartaria a necessidade da escrita) que a sabedoria advém das revelações contidas nos sonhos, da iluminação obtida por aqueles que, mediante a obediência às regras ditadas pelos mitos, estão mais próximas (sic) de Nhanderu e do conhecimento (Ladeira, 2007, p. 278).

Em oposição aos modelos de assimilação até então impostos pelo Estado ou por outros agentes (catequese, escolarização forçada, tutela e projetos de "integração"), a escola indígena diferenciada é uma conquista recente e em transformação. A violência colonial levou ao desaparecimento de centenas de povos, processo que tentam estancar a Constituição Brasileira de 1988 e alguns ordenamentos jurídicos internacionais recentes (como a Convenção 169 da $\mathrm{OIT}^{3}$ ), que visam a garantir direitos fundamentais às populações originárias, a começar pela retomada/reconhecimento de seus territórios e pela manutenção de línguas e modos de viver. No caso dos Mbyá, animais transitam livremente pelo espaço escolar; são compartilhados materiais e as produções prioritariamente construídas pelos alunos em colaboração; facilmente são utilizadas tecnologias e linguagens alheias na medida do que lhes pode ser útil; a escola é territorializada com plantas, alimentos e signos de pertencimento étnico, tudo isso pode ser sintetizado na disponibilidade para a tradução cultural. No entanto, como os conhecimentos indígenas não são disciplinares, nem disciplinados como demandam as instituições escolares, "Com tranquilidade, os índios tratam de ocupar espaços nas disciplinas, mas a experiência da cultura, dos saberes, está em outro lugar" (Gallois, 2016, p. 514).

\footnotetext{
${ }^{3}$ O governo brasileiro ratificou com o Decreto $\mathrm{n}^{\mathrm{o}} 5051$, de 19 de abril de 2004, o texto da Convenção $\mathrm{n}^{\circ} 169$ da Organização Internacional do Trabalho (OIT) sobre Povos Indígenas e Tribais, adotada em Genebra, em 27 de junho de 1989. Isso foi feito, "considerando que a evolução do direito internacional desde 1957 e as mudanças sobrevindas na situação dos povos indígenas e tribais em todas as regiões do mundo fazem com que seja aconselhável adotar novas normas internacionais nesse assunto, a fim de se eliminar a orientação para a assimilação das normas anteriores; reconhecendo as aspirações desses povos a assumir o controle de suas próprias instituições e formas de vida e seu desenvolvimento econômico, e manter e fortalecer suas identidades, línguas e religiões, dentro do âmbito dos Estados onde moram; observando que em diversas partes do mundo esses povos não podem gozar dos direitos humanos fundamentais no mesmo grau que o restante da população dos Estados onde moram e que suas leis, valores, costumes e perspectivas têm sofrido erosão frequentemente; lembrando a particular contribuição dos povos indígenas e tribais à diversidade cultural, à harmonia social e ecológica da humanidade e à cooperação e compreensão internacionais". Disponível em: http://www.planalto.gov.br/ ccivil_03/_ato2004-2006/2004/decreto/d5051.htm. Acesso em: 1ªbr. 2016.
} 
Nesse sentido, pode a prática narrativa compartilhada com não indígenas ser um desses lugares? Várias vezes foi perguntado ao professor interlocutor quando e por que contavam suas histórias, dado que a presença do Grupo na aldeia costumava ser restrita ao espaço escolar e suas imediações (áreas abertas e coletivas, como o pátio, o açude, a roça). A rigor, mesmo o que entendem por histórias não era dado estabelecido de antemão. Como foi mencionado anteriormente, as histórias eram veiculadas em língua portuguesa, o que criou uma barreira inicial com as crianças menores, dificuldade atenuada pela ênfase na linguagem do corpo e no emprego de alguns elementos cênicos (ver Figura 1). Era necessária a mediação do professor, que traduzia o narrado para o seu idioma. Por outro lado, a participação ativa das crianças era estimulada com alimentos a serem comidos, materiais a serem cheirados e tocados no sentido de reforçar aspectos sensoriais dos enredos. Segundo o professor, foi transformador na relação com as crianças o contato físico, ou seja, os abraços, as gargalhadas, as brincadeiras, afinal, "o argumento da presença de preocupações estéticas se encontrarem tanto na maneira de agir socialmente quanto na produção de qualquer artefato - especialmente quando se trata do 'artefato' mais valioso de todos, o corpo humano - vale para a quase totalidade dos povos ameríndios atuais" (Lagrou, 2009, p. 68). O fato de gostarem dessa presença fortemente corpórea funcionava como uma autorização para a continuidade da relação.

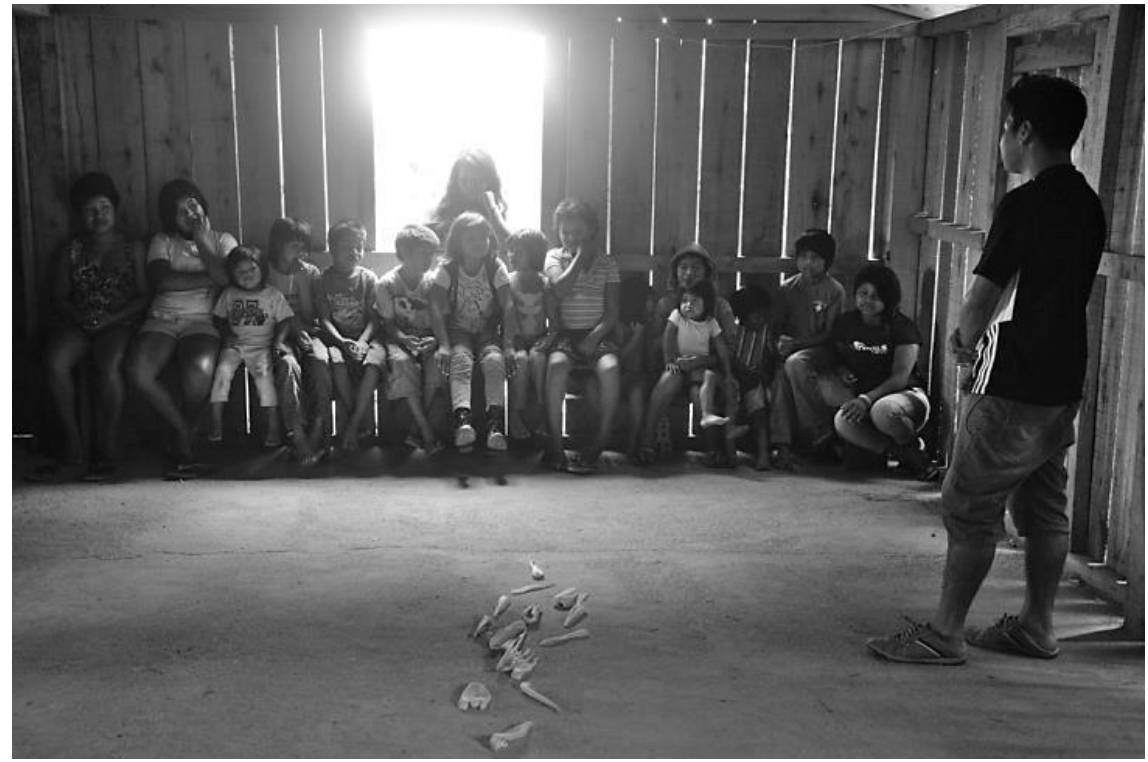

Figura 1 - Professor realizando a tradução durante a contação da história de "Kuaray e Jaxy". Fonte: acervo Quem Conta um Conto.

Em texto anterior, é reportada uma sequência de encontros que resultaram na construção artesanal de personagens e maquetes referentes à história "Festa no céu" conhecido conto popular brasileiro. A performance provocou o relato de uma curiosa versão do professor e, na sequência, uma série de atividades que culminaram numa narração coletiva e participativa. Cabe destacar que isso ocorreu após dois anos de trocas e experimentações permeadas por histórias guarani, brincadeiras e jogos não indígenas. Essa foi, assim, a primeira vez que, na escola e seus arredores, os Guarani apresentaram uma versão oral (em português e na língua materna, pelo professor) e uma leitura em voz alta (em português, pelos alunos maiores) da mesma história.

Após essa significativa partilha de imaginários e narrativas, foram se modificando as formas de relação. Além do convite para participar de atividades da/na aldeia (promovidas pelo cacique e lideranças, como festas abertas, saídas de campo), ao longo do primeiro semestre de 2015, o professor propôs nova modalidade de contato: participar do preparo e confecção do artesanato junto a outros moradores da aldeia (ver Figura 2). No primeiro dia da experiência, ofereceu o delicioso xipá, espécie de bolinho muito apreciado por eles. Compartilhar o alimento 
e o espaço-tempo é um modo profundo de se relacionar. Como nunca ocorrera antes, havia a proximidade das mulheres num fazer em comum em frente a suas casas. Como de hábito, e por não saberem (ou não quererem) falar português, mantiveram-se silenciosas junto a seus filhos enquanto tramavam a cestaria com motivos tradicionais.

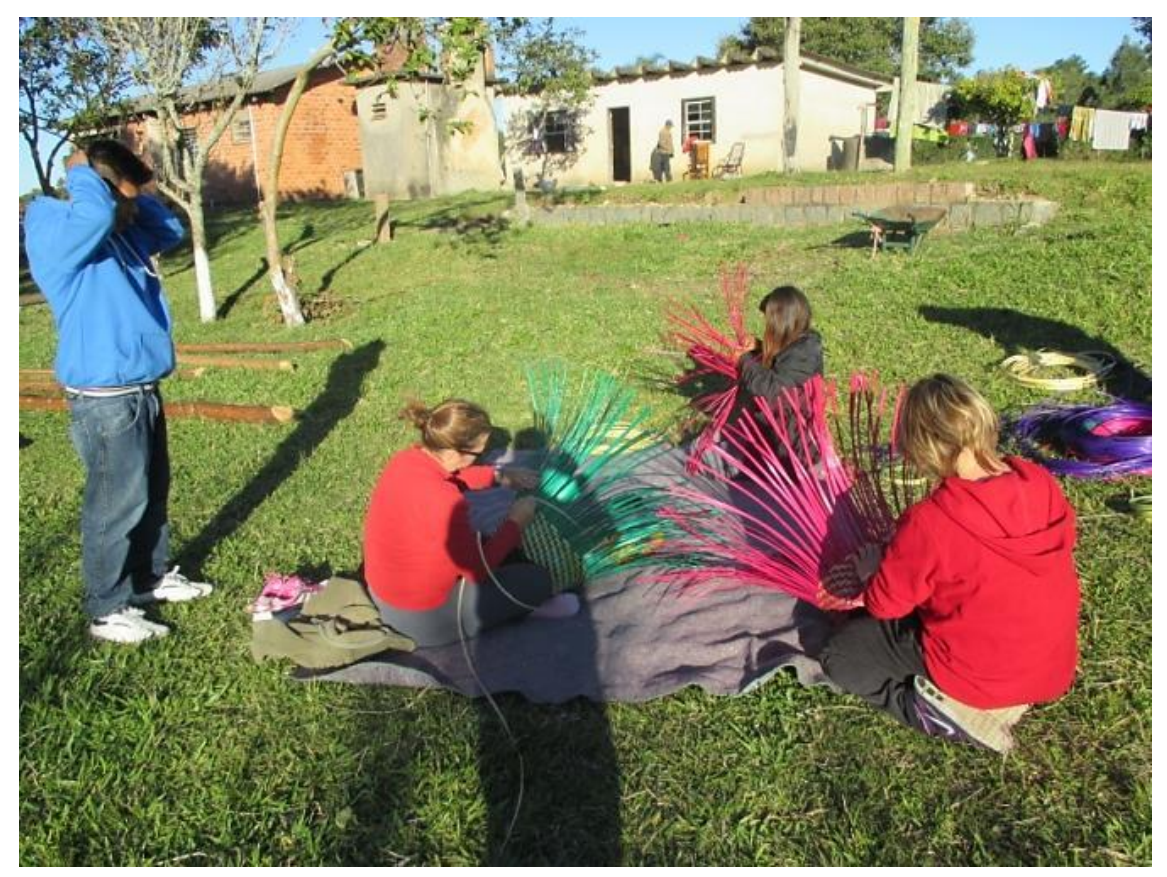

Figura 2 - Início do trabalho com as cestarias na Tekoá Anhetenguá. Fonte: acervo Quem Conta um Conto.

A interação ocorria no ato de fazer, desde a preparação e cortes das fibras das taquaras até o seu trançado, organizado em padrões geométricos orientados por mitos e códigos culturais, mas também pelas formas da natureza. A atividade coletiva, que tanto homens como mulheres podem vir a executar, permitiu acessar uma prática que atende tanto a significados socioeducativos como simbólicos. Os participantes são conhecedores do processo em sua totalidade, desde os tempos de cultivo e colheita da taquara, até os modos de aparar e separar as fibras ou de prover a quantidade necessária para determinado tipo de cesto. Os mais habilidosos são mais rápidos ou criam grafismos mais complexos, competência que requer ainda concentração na contagem dos intervalos em que uma fibra intercala movimentos por baixo ou por cima de outras, agrupadas em padrões matemáticos projetados com precisão. Nesse processo, que se prolongou por algumas semanas, houve a experiência de estar sob um ritmo lento e desafios motores e cognitivos em face de um todo orgânico, ou do "cosmosanimal" definido anteriormente por Rodolfo Kusch. Os corpos aprendiam nas relações, existiam de um outro jeito, inclusive através do cesto produzido em colaboração - algo como dar vida à matéria pela vontade de beleza. Fruía a sensação incomum de produzir o corpo enquanto era criado coletivamente um artefato sobre o qual se experimentara o processo de fatura (algo impensável na rotina urbana, que permite acesso a parte de sistemas e fluxos ignorados em sua grande parte, sob cerceamentos físicos e emocionais pelo tempo da acumulação, que não tolera as marcas da mão humana na irregularidade de alguma amarra, na torção de alguma fibra). A experiência partilhada coincide com o que Lagrou explica acerca da ação da obra de arte sobre as pessoas em suas relações, produções e existência.

A obra de arte, portanto, não serve somente para ser contemplada na pura beleza e harmonia das suas formas, ela age sobre as pessoas, produzindo reações cognitivas diversas. Se fossemos comparar as artes produzidas pelos indígenas com as obras conceituais dos artistas contemporâneos, encontraríamos muito mais semelhanças do 
que à primeira vista suspeitaríamos. [...] São objetos que condensam ações, relações, emoções e sentidos, porque é através dos artefatos que as pessoas agem, se relacionam, se produzem e existem no mundo (Lagrou, 2009, p. 13).

Em pesquisa em duas aldeias mbyá no Estado do Rio de Janeiro, é detalhado um processo simétrico a este. $\mathrm{O}$ pesquisador realiza com crianças oficinas de cerâmica, prática que os grupos revelaram ter abandonado. Pela via do pensamento e da articulação artístico-pedagógica, ressurge o manuseio poético com a argila e todo o possível eco que dele reverberasse em sua estrutura societal: “O imprescindível não é manter o objeto morfologicamente imutável, mas garantir o poder de permanência do que está 'por trás' dele: o caráter de produto surgido de dogmas baseados no ethos de sua vida comunal" (Alonso, 2015, p. 311). Assim, independentemente da variação estética das criações, houve, a seu ver, a conservação dos elos simbólicos e da posse comunicativa existente entre o objeto e a sua sociedade, com base na espiritualidade. Nesse caso, o que está por trás do objeto (arte/artesanato) é a própria cultura, que se revelava na aprendizagem pelo corpo e pelo contato entre corpos, processo desencadeado por um elemento não endógeno, no caso, o pesquisador. De modo semelhante, seriam as práticas de narrativa oral, entre elas a fatura dos cestos acima relatada, assim como as oficinas com o barro da experiência carioca, dispositivos para, fora da escola e em partilha, chegar ao que Gallois apontou como experiência da cultura (sem aspas) e dos saberes?

Tal experiência estético-cognitiva, de certa maneira, preparou o momento posterior, já no segundo semestre de 2015, deslocados para a terra indígena Ivy Poty. No sentido que entende Daniel Mato (2005), a colaboração intercultural permite observar não só o que outros sujeitos e grupos pensam, mas o que fazem com seus pensamentos, como se apropriam de conhecimentos e como os põem em relação com outras experiências. Nessa ocasião, foi narrado pelo grupo um mito de criação publicado num dos raros títulos de literatura desse povo (Jekupé, 2013). As peripécias dos irmãos Kuaray e Jaxy (Sol e Lua) remontam a uma visão cosmológica importante, ligada a constelações míticas de origem do povo. O companheirismo entre os irmãos e a criação de diferenças nos intentos desastrados de Lua imitar o irmão poderoso ilustram aspectos importantes dessa cosmologia: "O que é próprio e definidor das imitações, portanto, é menos o caráter moral de suas intenções e resultados, mas a inevitabilidade da produção da diferença. A imitação, aqui, não aponta para a identidade, mas para a variação, algo que parece ser fundamental em outras ontologias tupi-guarani, como aponta Gallois (2012) para o caso wajãpi" (Oliveira e Santos, 2016, p. 126). No mesmo dia, ouvimos do professor a versão por ele conhecida, em português e em guarani, esta dirigida aos estudantes. Ficou combinado que, num encontro posterior, haveria a narração dos estudantes dessa mesma história e de outras (ver Figura 3).

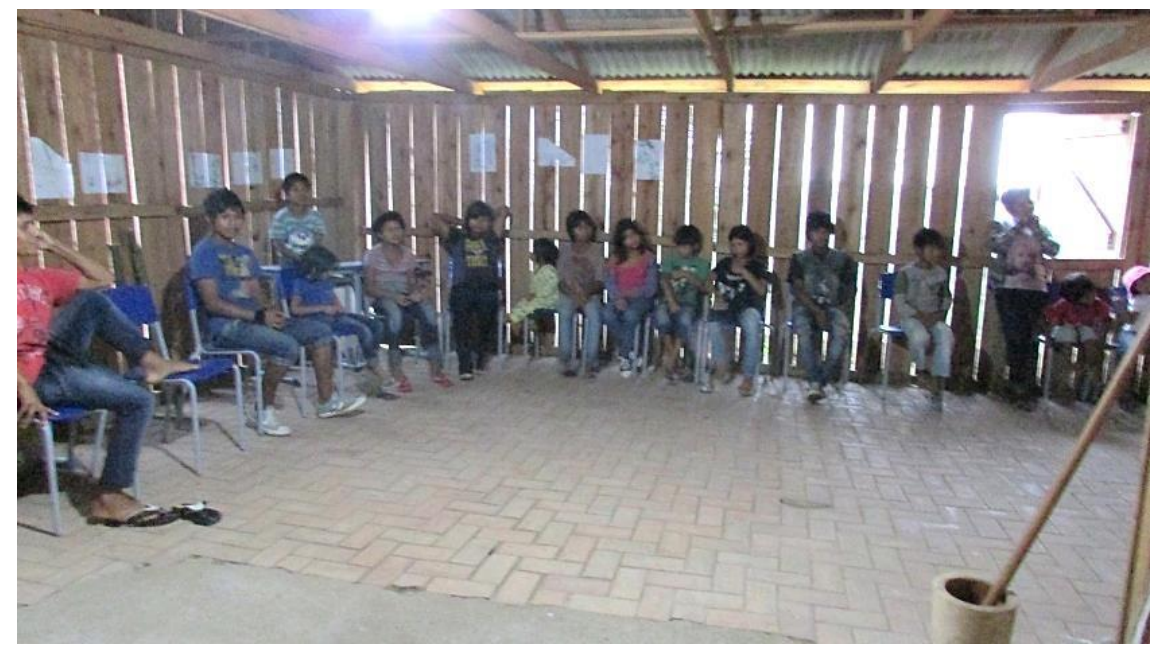

Figura 3 - Alunos contam histórias na escola da Tekoá Yvy Poty.

Fonte: acervo Quem Conta um Conto. 
No dia marcado, foram intercaladas várias histórias, muitas delas com animais e em sua maioria engraçadas. Tanto as crianças bem pequenas como as maiores participaram. Usaram a língua guarani, traduzida para o português pelo professor. Se antes a manifestação das crianças se dava como resposta a improvisos e convites para que "entrassem na história" (fosse cantando ou dançando, fosse atuando coletivamente como personagens), nesse dia, foram protagonistas. Por terem sido espectadores ativos de narrações anteriores, em sua performance tornava-se sensível e corpórea a apropriação do modo de contar do Grupo, que mais de uma vez disseram ser um "teatro". Havia alunos tanto no papel de um narrador que apresentava os fatos como no papel de personagens do enredo, com direito a falas decoradas e entoadas e uso de objetos e de gestos expressivos (como o menino que se lançou dramaticamente ao chão para mostrar a morte do personagem). Se a voz permaneceu no volume baixo e pausado de costume, a interpretação com certo acento caricato foi a maneira como corporalmente efetivaram a interculturalidade. $\mathrm{Ou}$, como mencionado anteriormente, os narradores mbyá demonstraram o conhecimento incidente sobre seus corpos, que se constrói por variações e pela diferença, como ensinaram os irmãos Kuaray e Jaxy do mito de origem.

Na negociação cultural, foram coautores de práticas sociais e estéticas que só existiram em copresença e pela sua participação ativa. Ao invés do ideal de autonomia artística, se efetivou ali a experiência da arte verbal que age sobre as pessoas mediante relações de alteridade e significados em seus corpos e sensações: "a maior parte das sociedades ameríndias situa no exterior a fonte de inspiração artística e cultural. [...] Estes elementos conquistados sobre - ou negociados com - o exterior precisam ser pacificados, familiarizados. Este processo de transformação do que é exterior em algo interior tem características eminentemente estéticas" (Lagrou, 2009, p. 56). Finalmente, sob a dinâmica estetizante do ritual, o encontro com a beleza nos eventos, corpos e objetos de uma sensibilidade voltada para o riso e para a alegria da vida, mesmo que esta seja marcada pela imperfeição.

Embora não tenham mais os territórios originais e os caminhos (oguatá) espirituais do passado e esbarrem em cercas e arames que os impedem de "sentir os passos e pisar o solo com respeito", conseguem negociar muitas coisas com o mundo não indígena sem enfraquecer sua perspectiva. Ao contrário, permitem, como no caso em tela, experimentar a transformação do que é exterior por meio das práticas em torno da palavra oral e da abertura ao outro não indígena, com quem negociam sentidos e a quem pacificam. É nesse sentido que esse escrito traz a criação artística que se faz para além da contemplação e da autoria individualizada, no lugar da interação e da potência estética coletiva.

\section{Referências}

ALONSO, Franklin da Silva (2015). Pulsões na arte mbyá-guarani: os seus pensamentos e sentimentos refletidos através dos objetos cerâmicos. Espaço Ameríndio, Porto Alegre, v. 9, n.1, p. 303-320, jan./jun.

BENJAMIN, Walter (1987). Rua de mão única. Tradução de Rubens Rodrigues Torres Filho. São Paulo: Brasiliense. (Obras Escolhidas, v. 2)

BRASIL (1988). Constituição da República Federativa do Brasil. Brasília, DF: Senado Federal. Disponível em: http://www.planalto.gov.br/ccivil_03/constituicao/constituicao.htm. Acesso em: 20 abr. 2016.

CUNHA, Manuela Carneiro da (2009). "Cultura" e cultura: conhecimentos tradicionais e direitos intelectuais. In: CUNHA, Manuela Carneiro da. Cultura com aspas. São Paulo: Cosac Naify. p. 311-373.

CESARINO, Pedro de Niemeyer (2006). De duplos e estereoscópios: paralelismo e personificação nos cantos xamanísticos ameríndios. Mana, Rio de Janeiro, v. 12, n. 1, p. 105-134.

FIOROTTI, Devair; OLIVEIRA, Jociane Gomes de (2016). Erencon, a literatura e os haicais. Revista Boitatá, Londrina, n. 22, p. 49-67, jul./dez. 
GALLOIS, Dominique Tilkin (2016). A escola como problema: algumas posições. In: CUNHA, Manuela Carneiro da; CESARINO, Pedro de Niemeyer (Org.). Políticas culturais e povos indígenas. São Paulo: Editora da Unesp. p. 509-517.

JEKUPÉ, Olívio (2013) (Org.). As queixadas e outros contos guaranis. Ilustrado por Fernando Vilela. São Paulo: FTD.

KUSCH, Rodolfo (2009). El pensamento indígena y popular en América. In: KUSCH, Rodolfo. Obras completas. Rosário: Fundación A Ross. p. 255-546.

LADEIRA, Maria Inês (2007). O caminhar sob a luz. São Paulo: Editora Unesp.

LAGROU, Els (2009). Arte indígena no Brasil: agência, alteridade e relação. Belo Horizonte: C/Arte.

LIMA, Joaquim Maná de et al. (2016). Observações sobre o processo de patrimonialização dos Kene Huni Kuĩ. In: CUNHA, Manuela Carneiro da; CESARINO, Pedro de Niemeyer (Orgs.). Políticas culturais e povos indígenas. São Paulo: Editora da Unesp. p. 219-240.

MATO, Daniel (2005). Interculturalidad, producción de conocimientos y prácticas socioeducativas. Alceu, Rio de Janeiro, v. 6, n. 11, p. 120-138, jul./dez.

MENEZES, Magali Mendes et al (2015). Um olhar sobre o olhar indígena e suas escol(h)as. Education policy analysis archives, San Andrés, v. 23, n. 97, p. 1-29, out. Disponível em: http://epaa.asu.edu/ojs/article/view/2044/1678. Acesso em: 12 ago. 2016.

OLIVEIRA, Joana Cabral de; SANTOS, Lucas Keese dos (2016). "Perguntas demais" - multiplicidades de modos de conhecer em uma experiência de formação de pesquisadores Guarani Mbya. In: CUNHA, Manuela Carneiro da; CESARINO, Pedro de Niemeyer (Org.). Políticas culturais e povos indígenas. São Paulo: Editora da Unesp. p. 113-133.

PISSOLATO, Elizabeth (2008). Dimensões do bonito. Espaço Ameríndio, Porto Alegre, v. 2, n. 2, p. 35-51, jul./dez.

RIBEIRO, Berta (1986a). Introdução. In: RIBEIRO, Berta (Coord.). Suma etnológica brasileira. Petrópolis: Vozes, v. 2, p. 18-27. Disponível em: http:/ / www.etnolinguistica.org/suma. Acesso em: 11 jul. 2016.

RIBEIRO, Darcy (1986b). Arte índia. In: RIBEIRO, Darcy (Ed.) et al. Suma etnológica brasileira. Petrópolis: Vozes, v. 3, p. 27-54. Disponível em: http://www.etnolinguistica.org/suma. Acesso em: 11 jul. 2016.

RISÉRIO, Antônio (1993). Textos e tribos: poéticas extraocidentais nos trópicos brasileiros. Rio de Janeiro: Imago.

TETTAMANZY, Ana Lúcia Liberato; RIVOIRE, Luciene (2013). Histórias para povoar as matas: os MbyáGuarani entre voz e letra. In: FARENZENA, Nalu (Org.). ENCONTRO INTERNACIONAL DE INVESTIGADORES DE POLÍTICAS LINGUÍSTICAS, 6., 23-25 nov 2013. Porto Alegre: UFRGS. p. 218-225.

VIDAL, Lux; SILVA, Aracy Lopes da (1995). O sistema de objetos nas sociedades indígenas: arte e cultura material. In: SILVA, Aracy Lopes da; GRUPIONI, Luís Donisete Benzi (Orgs.). A temática indígena na escola. Brasília: MEC, p. 369-406.

VIEIRA, Marina Guimarães (2016). Sobre alguns modos de usar a cultura dos Outros. In: CUNHA, Manuela Carneiro da; CESARINO, Pedro de Niemeyer (Org.). Políticas culturais e povos indígenas. São Paulo: Editora da Unesp. p. 257-286. 